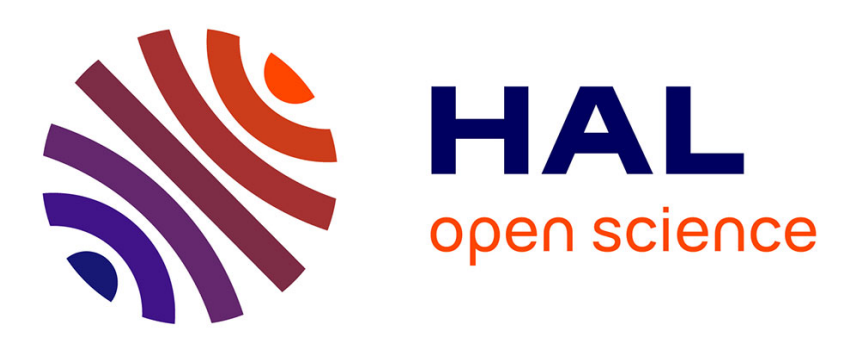

\title{
Safety of avoiding routine use of axillary dissection in early stage breast cancer: a systematic review
}

\author{
Manon J. Pepels, Johanna H. M. J. Vestjens, Maaike Boer, Marjolein Smidt,
} Paul J. Diest, George F. Borm, Vivianne C. G. Tjan-Heijnen

\section{To cite this version:}

Manon J. Pepels, Johanna H. M. J. Vestjens, Maaike Boer, Marjolein Smidt, Paul J. Diest, et al.. Safety of avoiding routine use of axillary dissection in early stage breast cancer: a systematic review. Breast Cancer Research and Treatment, 2010, 125 (2), pp.301-313. 10.1007/s10549-010-1210-7 . hal00588492

\section{HAL Id: hal-00588492 https://hal.science/hal-00588492}

Submitted on 24 Apr 2011

HAL is a multi-disciplinary open access archive for the deposit and dissemination of scientific research documents, whether they are published or not. The documents may come from teaching and research institutions in France or abroad, or from public or private research centers.
L'archive ouverte pluridisciplinaire HAL, est destinée au dépôt et à la diffusion de documents scientifiques de niveau recherche, publiés ou non, émanant des établissements d'enseignement et de recherche français ou étrangers, des laboratoires publics ou privés. 


\section{Safety of avoiding routine use of axillary dissection in early stage breast cancer: A systematic review}

Manon J. Pepels ${ }^{1}$, Johanna H.M.J.Vestjens ${ }^{1}$, Maaike de Boer ${ }^{1,5}$, Marjolein Smidt ${ }^{2}$, Paul J. van Diest ${ }^{3}$, George F. Borm ${ }^{4}$, Vivianne C.G. Tjan-Heijnen ${ }^{1}$

${ }^{1}$ Division of Medical Oncology, Department of Internal Medicine, and ${ }^{2}$ Department of Surgery, GROW - School for Oncology and Developmental Biology, Maastricht University Medical Centre, Maastricht; ${ }^{3}$ University Medical Centre Utrecht, Utrecht; ${ }^{4}$ Department of Epidemiology, Biostatistics and HTA, Radboud University Nijmegen Medical Centre, Nijmegen; ${ }^{5}$ Department of Medical Oncology, Radboud University Nijmegen Medical Centre, Nijmegen

\section{Address for correspondence:}

Vivianne C.G. Tjan-Heijnen, M.D., Ph.D.

Division of Medical Oncology, Department of Internal Medicine Maastricht University Medical Centre

P.O. Box 5800

6202 AZ Maastricht, the Netherlands

phone $+31433877025 ;$ fax +31433876281

email: vcg.tjan.heijnen@mumc.nl

\section{Funding:}

Netherlands Organization for Health Research and Development (ZonMw 945-06$509)$.

Keywords Breast cancer - sentinel node - axillary lymph node dissection - axillary recurrence - survival 


\section{Abstract}

Purpose Physicians are moving away from routine axillary lymph node dissection (ALND) in clinically node-negative breast cancer. We conducted a systemic review on the safety of this policy.

Methods Pubmed and Cochrane library were searched for. Sixty-eight studies were included: studies of clinically node-negative patients in the pre-sentinel node (SN) era; observational studies of SN-negative patients, without ALND; comparative studies of SN-negative patients, with a non-ALND and an ALND group; SN-positive studies, of patients without ALND. Primary endpoint was the pooled axillary recurrence rate $(A R R)$ of each category; secondary endpoint was overall survival (OS) rates.

Results In pre-SN studies, with larger tumors and less systemic therapy, ARR without ALND after 5 to 10 years follow-up was $12-18 \%$, with $5 \%$ reduced OS. In the observational SN-negative studies, with median follow-up of 36 months, the pooled ARR was $0.6 \%(95 \% \mathrm{Cl} 0.6-0.8)$. In the comparative SN-negative studies, pooled ARR was $0.4 \%(95 \% \mathrm{Cl} 0.2-0.6)$ without $A L N D$ versus $0.3 \%(95 \% \mathrm{Cl} 0.1-0.6)$ with ALND at 31 and 47 months, respectively, and no survival disadvantage. In SNpositive studies, ARR was up to $1.7 \%(95 \% \mathrm{Cl} 1.0-2.7)$ at 30 months. For patients with an H\&E positive SN the ARR without ALND was $5 \%$ after 23 months, which may imply rates as high as $13 \%$ and $18 \%$ after 5 and 8 years.

Conclusion This systematic review confirms the safety of omitting ALND in SNnegative patients. There is a potential role for avoiding ALND in selected SN-positive patients, but eligibility criteria and the role of systemic therapy need further to be elucidated. 


\section{Introduction}

Axillary lymph node dissection (ALND) has long been considered the golden standard in the work-up of early stage breast cancer patients. It offered as such the best opportunity for staging and prognostication to select patients requiring additional treatment. Whether ALND also offers a therapeutic advantage is questioned [1].

Nowadays, approximately 60 to 70 percent of breast cancer patients have nodenegative disease, due to an earlier diagnosis of breast cancer [2]. Obviously, if the axillary lymph nodes are truly negative, there can be no possible benefit from performing an ALND. In the late nineties, the sentinel lymph node (SN) procedure was introduced $[3,4]$. The intrinsic hypothesis is that SN biopsy will identify patients with a negative axilla on pathology. The false-negative rate of the SN procedure is on average $8.4 \%$, ranging from 0 to $29 \%$ [5]. Based on the low false-negative rate, the $\mathrm{SN}$ procedure was rapidly implemented in routine daily practice, even before the first randomized trial on the safety of the SN procedure was finalized $[6,7]$.

In The Netherlands at least $70 \%$ of breast cancer patients undergo an SN procedure. Of these patients, in $65 \%$ an $\mathrm{SN}$ only is carried out, implying, that in daily practice in nearly $50 \%$ of newly diagnosed breast cancer patients ALND is avoided [7]. (Completion) ALND is still the standard of care for patients with axillary metastases being identified by SN biopsy, including micrometastases [5].

To this end, many series have reported on axillary recurrence rates (ARRs). A few randomized trials evaluated the safety of the SN procedure. Recently, attention was drawn to the fact that there is a trend towards omitting ALND in patients with micrometastatic involvement of the $\mathrm{SN}$, in contrast to the ASCO recommendations and despite lack of data on the safety of this strategy [8]. 
The aim of our study was to provide a systematic review on the safety of withholding ALND to clinically-node negative breast cancer patients. For this purpose we reviewed ARRs in the pre-SN era of patients who did or did not undergo an ALND, and we reviewed ARRs of patients with a negative or positive SN in observational series and randomized trials that did or did not undergo a completion ALND. As secondary endpoint we reviewed survival rates in relation to axillary surgery type.

\section{Methods}

\section{Literature Search Strategy}

We performed a systematic review of the literature. Pubmed and the Cochrane Library were searched for ( $1^{\text {st }}$ of January 1985 through $30^{\text {th }}$ September 2009) with the use of the Medical Subject Heading terms 'breast neoplasm', 'sentinel node', 'axillary lymph node dissection', 'recurrence' and 'survival'. We only included studies which were published in English language. Studies were included irrespective of number of patients included, except for case reports.

\section{Study Inclusion Criteria}

The following criteria were applied to the papers that were identified by the literature search. Studies were included when they studied ALND and/or axillary staging by the SN procedure if follow-up information was provided. Endpoints had to be available in terms of ARR and/or overall survival (OS) rates. Studies that reported on detection methods using molecular biology approaches like reverse transcriptase polymerase chain reaction, and studies in which neoadjuvant chemotherapy was 
administered were excluded. If duplicate or updated studies were identified, only the most recent study was included. Only full papers published in peer-reviewed journals and based on original data were included. Retrospective large database studies analyzing OS were only included if more than 1,000 patients were included. To prevent overlap of data from studies that described subpopulations besides a total population, only the total population was taken into account, and the most recent paper. For cohort studies and series based on overlapping selections, only the largest study was taken into account.

\section{Data Extraction}

Two independent investigators (MP and JV) extracted data to rule out potential bias or errors. Discrepancies were resolved by consensus, if necessary through arbitrage by a third investigator (VTH). The following data were extracted from the included papers: number of patients studied, tumor size or stage, follow-up time, false-negative rate, ARR, OS, type of surgery, number of nodes excised, use of adjuvant systemic therapy, use of axillary radiotherapy. Complete data were not always obtainable for every characteristic evaluated in each study. For some studies the range for time of follow-up had to be estimated based on date of inclusion versus date of analysis and/or date of manuscript submission. If not provided in the text or tables in the original paper, data with respect to ARRs were extracted from the recurrence-free survival curves. In some series, patients with in situ carcinoma were included; these patients were omitted in our tables, with recalculation of the ARR for invasive cancers only.

\section{Definitions}


The false-negative rate was obtained by dividing the number of patients who were $\mathrm{SN}$-negative but non-SN positive by the number of patients who had a positive SN or a positive non-SN. This shows the reliability of the SN procedure, i.e., the sensitivity of the SN procedure is 1 minus the false-negative rate. This is essentially different from the percentage of patients with a negative $\mathrm{SN}$, having a positive nonSN (1 minus negative predictive value). This percentage was collected or calculated and shown in the table regarding the validation and randomized studies. If a different definition was used in a paper, or if in situ carcinoma was included in the denominator, the rate was recalculated.

Of note, if in a study axillary recurrence was reported as either isolated or in combination with local or distant relapse, the total number of axillary recurrences was counted. In most papers median (or mean) tumor size and T-stage were only described for the total population, both with a negative SN and positive SN. This overall number was then used in the tables.

\section{Statistical Analyses}

Most studies were very small and only reported summary statistics for the exposure and the recurrence, such as median exposure time and number of recurrences. As no estimates of efficacy were reported, for example a 5 or 10 years recurrence rate, a routine meta-analysis was impossible. Hence, we used a more informal approach and calculated the overall recurrence by dividing the total number of recurrences by the total number of patients in all studies. In addition, we estimated the median exposure by the weighted median of the median exposure times in the studies, with study size as weight. 
For the single group studies, we were able to calculate Kaplan Meier estimates of the pooled 5 and 8 years ARRs. As we did not have the individual patient data, we had to estimate the follow-up duration for each patient. For patients who did not have a recurrence, we used three different scenarios. Middle scenario: almost all studies reported minimal, median and maximal duration of follow-up. In this scenario, we assumed that the follow-up durations were uniformly distributed, with half of the durations between the minimum and median follow-up and half of the durations between the median and maximum follow-up. For three studies [9-11] , no minimal follow up was reported, and we assumed it to be 0 . When no maximal follow up was reported (one study) [12], we assumed it to be twice the upper quartile. Worst case scenario: we assumed that $40 \%$ of the follow-up durations were equal to the minimum follow-up. The others were uniformly distributed, as in the middle scenario. In the worst case scenario, the follow-up duration is low, so the estimate of the recurrence rate will be high. Best case scenario: we assumed that $40 \%$ of the exposures were equal to the maximum follow-up duration. The others were uniformly distributed, as in the middle scenario.

In most studies, for patients that had a recurrence, the time of the recurrence was reported, so no assumptions about the follow-up duration were required. For the four studies, that only reported median, minimal and maximal duration till recurrence, we followed a similar approach as described above, using a middle, a worst and a best case scenario. For two studies with one event, the duration till recurrence was not reported and we set it to the median follow-up [13].

The worst and best case scenarios are extremely conservative, because they assume worst and best case scenarios in every individual study. In practice, different 
studies probably had different follow up patterns that more or less cancelled each other out. We therefore think that the middle scenario is the most realistic.

In addition to the approach above we investigated the results when the exposure data were not uniformly distributed, but followed a Weibull distribution.

Further, we calculated pooled survival rates for the three randomized SN studies. For the large database pre-SN studies we were not able to calculate pooled survival rates, because of large heterogeneity between studies.

All reported p-values are two-sided, and confidence intervals $(\mathrm{Cl})$ are at $95 \%$ level. All analyses were performed in SAS (version 8.2).

\section{Results}

This search strategy resulted in 61 abstracts. The reference lists of selected papers were searched for additional papers, leading to the identification of in total 68 eligible studies which included follow up of different axillary treatment strategies.

We decided to categorize the included studies according to type of axillary surgical approach. In this way, we aimed to show more clearly the differences and similarities between studies on the issue of ARR and OS. The first category consisted of studies of patients with clinically node-negative disease who did or did not undergo a conventional ALND, in the pre-SN era, with a long-term follow-up. The second category consisted of observational studies of patients who had a negative SN and who did not undergo a completion ALND. The third category consisted of comparative studies with a non-ALND and an ALND group. All patients had a negative $\mathrm{SN}$ and in the learning phase, one group of patients underwent a completion ALND, whereas the more recent patients did not undergo a completion 
ALND anymore (i.e., validation and application phase studies). We also included randomized studies assessing the safety of the SN procedure in this category. The fourth category included observational studies that reported follow-up data on patients with a positive SN who did not undergo a completion ALND. The last category concerned studies that reported on at least 5-years follow-up data on survival rates in either pre-SN or SN era.

\section{ARRs with versus without conventional ALND: Pre-SN studies}

To evaluate the role of ALND in patients with clinically node-negative disease in the pre-SN era, we included 3 randomized trials comparing ALND versus no axillary treatment $[14,15]$ (Table 1).

In the NSABP B-04 trial, after a follow-up of ten years the ARR was $18.4 \%$ in the total mastectomy group as compared to $1.4 \%$ in the radical mastectomy group, including ALND, even though it was noted that a small number of lymph nodes was excised in one third of the patients in the 'no axillary treatment arm' [15]. Site of recurrence was only reported for the first event, which may have resulted in an underreported ARR.

ALND was compared to axillary radiotherapy in five randomized studies[14,1618]. In two of these, the Guy I and Guy II trials, the radiotherapy dosage in the noALND arms was considered inadequate to modern standards for axillary radiotherapy [14], and for that reason these two latter studies were considered of interest for our systematic review. The ARRs were $18.8 \%$ and $12.5 \%$ without ALND compared to $0.9 \%$ and $1.4 \%$ with ALND, in the Guy I and Guy II trials respectively after 5 to 10 years of follow-up, in agreement with findings in the B-04 trial. The difference in 
outcome between the Guy I and Guy II trial could be explained by the fact that there were significantly more patients with $\mathrm{T} 1$ tumors in the Guy II trial.

\section{ARRs for a negative SN, without ALND: observational studies}

Of 50 observational SN studies [9-13, 19-63], information on ARRs was available of patients who had a negative $\mathrm{SN}$ and who had not undergone a completion ALND (Table 2, Figure 1). There was a large difference in tumor size and administered systemic therapy between studies.

Overall, follow-up of more than 26,000 patients was reported. The median and maximum follow-up duration of all studies pooled was 36 and 144 months, respectively. With a median follow-up duration of 36 months, the ARR was $0.6 \%$ (95\% Cl 0.6-0.8).

Fig. 1 shows the Kaplan-Meier curves for the middle, best and worst case scenarios. According to the middle scenario, the 5- and 8-years ARRs were 1\% $(95 \% \mathrm{Cl} 0.8-1.1)$ and $1.4 \%(95 \% \mathrm{Cl} 1.1-1.6)$, respectively. In the worst case scenario, the recurrence rates were approximately $0.1 \%$ worse.

\section{ARRs for a negative SN, with and without ALND: comparative studies}

The third category consisted of studies in which patients with a negative SN were randomized between a completion ALND or not, and of studies in which patients with a negative $\mathrm{SN}$ in the learning / validation phase routinely underwent a completion ALND, whereas the next patients with a negative $\mathrm{SN}$ did not undergo a completion ALND anymore (SN application phase) (Table 3).

In total, 12 studies $[7,10,12,13,24,33,35,41,42,43,52,54,64]$ were available with follow-up information, of which three $[6,7,10,13,41]$ were randomized. Overall, follow- 
up of 8,542 patients was reported. The ARR was $0 \%$ in all but three 'SN and ALND' study arms, leading to an overall recurrence rate of $0.3 \%(95 \% \mathrm{Cl} 0.1-0.6)$. As in one of these it was actually unclear whether the only patient with an axillary recurrence had a negative or positive SN, the recurrence rate may even be lower [10]. The median follow up duration in these studies was 47 months, with a maximum of 102 months.

On the other hand, the pooled recurrence rate for SN negative patients who did not undergo a completion ALND was $0.4 \%(95 \% \mathrm{Cl} 0.2-0.6)$, which is still low but slightly higher compared with the SN-negative ALND-treated patients, especially when considering the shorter median follow up duration of only 31 months, with a maximum of 98 months.

The false-negative rate ranged from 4.1 to $22.2 \%$. Conversely, the percentage of patients with a negative SN having a positive non-SN varied from $2.0-9.2 \%$. This latter rate reflects the potential long term risk of axillary recurrence if no systemic treatment is offered.

\section{ARRs for a positive SN, without ALND: observational studies}

One population-based study [65] and fifteen single centre studies $[12,23,35,42,43,46,50,55,66-72]$ reported on patients with a positive SN who did not undergo a completion ALND (table 4).

From the National Cancer Data Base of the United States of America, nearly 100,000 patients with clinically node-negative breast cancer who had a positive SN were identified [65]. Of these, $21 \%$ underwent SN only ( $n=1,988$ patients). In this population based study, $1 \%(95 \% \mathrm{Cl} 0.6-1.5)$ of the patients had a recurrence, while the median duration of follow up was 64 months, with a maximum of 72 months. The 
authors themselves noted already that recurrences may have been underreported to cancer registries. Patients with micrometastases who did not undergo ALND probably included isolated tumor cells according to the $6^{\text {th }}$ edition of AJCC classification [73], implying that a substantial number of patients actually may have had 'node-negative disease' according to current definition.

The pooled single centre studies resulted in $1.7 \%(95 \% \mathrm{Cl} 1.0-2.7)$ recurrences, with a median and maximum follow-up duration of 30 months and 98 months, respectively. Overall, follow-up was reported from 962 patients.

In the largest single centre study from the MSKCC $(n=287)$, patients with SN positive / no ALND had compared with the SN positive / ALND patients more favorable tumors with a lower median predicted risk of non-SN metastases (9\% versus $37 \%, P<0.001$ ) [67]. The SN metastasis size was not reported, but SN positivity was detected by serial sectioning and/or immunohistochemistry in $39 \%$ of patients, indicating small volume disease in many patients. Of note, in the 'no ALND' group, still a substantial number of nodes was excised, that is, 4 or more nodes (SN and non-NSs) in $14 \%$ of patients. And, fifteen percent of patients received radiotherapy to the axilla and/or supraclavicular nodes. In their series, axillary recurrences developed in $2.0 \%$ of SN positive / no ALND patients at a median followup of 23 months versus in $0.4 \%$ of SN positive /ALND patients at 30 months $(P=.004)$. Of importance, the highest ARR was seen in the subgroup of SN positive / no ALND patients whom SNs were positive on routine H\&E. In these patients the ARR was $5 \%$ after 23 months of follow-up.

In the second largest study, from the MD Anderson Cancer Center, 196 patients with a positive SN did not undergo completion ALND [66]. Twenty-three patients had non-SNs removed, and relatively many SNs (median 4, range 1-14) were excised. 
Radiotherapy covering part of the axilla was used in $64 \%$ of patients. The calculated risk of positive non-SNs based on the MSKCC nomogram was $9.8 \%$, in line with the low risk profile according to the MDACC risk model. At a median follow-up of 30 months, no axillary recurrences were observed.

\section{OS in randomized and large database studies: pre-SN and SN studies}

Before the SN era, 6 randomized trials have assessed the role of ALND with respect to survival in clinically node-negative breast cancer patients (Table 5). Three of six studies, among others the NSABP-B04, did not show a statistically significant survival benefit, but likely due to lack of power. Although 3 studies used axillary radiotherapy in patients who did not undergo an ALND, these studies were yet included in the analysis [16-18] . In a Bayesian meta-analysis, the combination of trials including almost 3,000 patients showed a $5.4 \%(95 \% \mathrm{Cl} 2.7-8.0)$ survival benefit in favor of ALND [74]. Of note, essentially none of the patients were treated with systemic therapy.

In addition, six large pre-SN database-studies, including in total 160,459 patients, showed a survival benefit in direct proportion to the number of lymph nodes removed (Table 5) [75-80]. Although it was noted that treatment choices may have been influenced by age, presence of co-morbidity and likelihood of nodal involvement, these were not always taken into account in multivariate analyses. Only one study corrected for use of systemic therapy and observed that the risk of death by omission of ALND was diminished when systemic therapy was used [77]. Another interesting observation was that even when all regional lymph nodes were pathologically negative, the number of nodes removed was associated with survival [78-79]. 
The three published studies randomizing patients to ALND or to SN followed by ALND only if the SN was involved did not show a survival benefit of ALND, and concluded that completion ALND can be avoided in patients with negative SNs $[10,13,41]$. Pooled analysis of the three randomized trials also showed no significant differences in 5-year OS, with a hazard ratio of $-0.2(95 \% \mathrm{Cl}-2.4 \%, 2.2 \%)$.

\section{Discussion}

In patients with clinically node-negative breast cancer the necessity of axillary surgery has been a matter of debate for many years. Leaving out ALND in all clinically-node negative patients is potentially harmful [74]. With the introduction of the SN procedure a strategy to identify the patients who might not need axillary surgery became available. The aim of our study was to provide a systematic review to estimate ARRs in patients with clinically node-negative breast cancer, who did or did not undergo ALND. In this systematic review, we found that patients with a negative SN had a pooled ARR of only $0.6 \%$ at 36 months. In contrast, in SN-positive studies the ARR was about 3 times higher, up to $1.7 \%(95 \% \mathrm{Cl} 1.0-2.7)$ at 30 months. For patients with a positive SN by H\&E examination these rates were even higher.

The SN procedure is based on the premise that it improves identification of patients with pathologically node-negative disease. Indeed, series including patients with a negative SN who did not undergo completion ALND show low ARRs of $1 \%$ after 5 years of follow-up (Fig. 1). The results of the comparative studies, i.e. summary statistics of the follow-up duration and overall recurrence, are more difficult to interpret (Tables 2 and 3 ). The observational study results may illustrate this. The overall recurrence rate in these studies was $0.6 \%$, the median follow-up was 36 months and the maximal follow-up was 12 years. One may be tempted to assume 
that $0.6 \%$ is the recurrence rate at median follow-up, or at least for some time point between the median and the maximum follow up duration. However, the Kaplan Meier graph in Fig. 1 shows that the recurrence rate at median follow up is already $0.8 \%$ and it is steadily increasing to more than $1.5 \%$ after 9 years. So, in reported studies the ARR continued to increase over time, which was different from what we had expected. Based on the comparative studies, we conclude that omitting ALND in $\mathrm{SN}$ negative patients is associated with a small increase in risk of axillary recurrence. However, based on the single group studies, we conclude that this risk seems to be acceptable as long as techniques are validated and selection criteria do not change dramatically from the criteria in validated studies. New prospective randomized survival and regional recurrence data from the NSABP B-32 were very recently presented at ASCO [81]. In B-32, including 2,011 pathologically node-negative patients undergoing $\mathrm{SN}$ alone and 1,975 randomized to $\mathrm{SN}$ plus confirmatory axillary dissection, the SN biopsy false-negative rate was $9.8 \%$ with a sample size large enough to detect a $2 \%$ difference in survival between the control and experimental arms [81,82]. Median follow-up was 95 months. ARRs were $0.6 \%$ and $0.4 \%, 5$-year OS rates were $95.0 \%$ and $96.4 \%$, respectively, both statistically not different. This recent study supports the view that in SN negative breast cancer patients with a T1 or (small) T2 tumor, omission of ALND can be regarded as safe.

In daily practice there is a shift toward omitting completion ALND in SN positive patients $[8,65,83]$. At first glance, ARRs in series and a population-based registry seem not worse as opposed to series in SN negative patients (Table 4 versus Tables 2 and 3). However, these low recurrence rates in $\mathrm{SN}$ positive patients may be explained by more favorable tumor characteristics, the presence of isolated tumor cells (even if they were classified as "micrometastases"), a considerable number of 
patients being treated by axillary radiotherapy, and finally, the number of nodes removed during the $\mathrm{SN}$ procedure being higher than normally expected. Of note, the MSKCC reported that in patients identified with a positive SN by H\&E examination, the ARR was $5 \%$ at a median follow-up of 23 months, even though these were highly selected patients [67]. In a cohort study from The Netherlands (the MIRROR study), patients with $\mathrm{SN}$ micrometastases $(0.2-2.0 \mathrm{~mm})$ who did not undergo a completion ALND were also shown to have an increased risk of axillary recurrence of $5 \%$ at 5 years follow-up [84].

The results of the observational SN negative studies may help to interpret the results for $\mathrm{SN}$ positive patients. On the one hand, the single group $\mathrm{SN}$ negative studies had a median follow-up duration of 36 months and an overall recurrence of $0.6 \%$. The 5 and 8 year recurrence rates were $1 \%$ and $1.4 \%$ respectively. For the studies in $\mathrm{SN}$ positive patients, the overall recurrence was $1.7 \%$, i.e. $1.7 / 0.6=2.8$ times higher than for the single group studies. Therefore, the 5 and 8 year recurrence rates in SN positive patients may be $(1.7 / 0.6)^{*} 1=2.8 \%$ and $(1.7 / 0.6)^{*} 1.4=4 \%$, respectively. If we also take the median follow-up of 30 months for the SN positive studies into account, the rates will be $(36 / 30)^{\star} 2.8=3.4 \%$ and $(36 / 30)^{*} 4=4.8 \%$, respectively. In a similar way, we find that for patients identified with a positive SN by H\&E examination in the MSKCC study, the ARR after 5 and 8 years may be as high as $(5 / 0.6)^{*}(36 / 23)^{*} 1=13 \%$ and $(5 / 0.6)^{*}(36 / 23)^{*} 1.4=18 \%$. Although these calculations are rather speculative, they are not implausible. They suggest that in many patients with a positive SN withholding ALND may not be safe. Concerns regarding safety of general omission of ALND in clinically node-negative but SN positive patients is based on the survival rates in conventional ALND versus no-ALND studies [74]. However, in these studies most of the patients did not receive adjuvant systemic 
therapy. Recently, we showed that isolated tumor cells and micrometastases were associated with a reduced 5-year rate of disease-free survival among women with favorable early-stage breast cancer who underwent an SN procedure and who did not receive adjuvant systemic therapy [85]. Among patients who received systemic therapy, the 5-year disease-free survival rate was significantly improved with an absolute benefit of nearly 10 percent, including a reduction in locoregional recurrence rate. Therefore, with more patients undergoing systemic therapy, the need for axillary treatment may change. In the studies reported so far, the rate of systemic therapy was highly varying and, therefore, impossible to analyse. This is a limitation of a systematic review on published data instead of a meta-analysis on individual data. Considering the number of trials and low number of patients included, an individually based analysis was considered not possible.

Survival outcomes for the node-positive ACoSOG Z0011 trial were presented at ASCO [82]. Patients with one or two H\&E positive SNs were randomized to observation or ALND. The trial unfortunately failed to reach its targeted accrual. This otherwise would have been the most robust possible test of the null hypothesis that regional lymph node dissection does not improve breast cancer outcomes. That noted, among the 856 patients randomized and analyzed in an intent-to-treat analysis, at a median follow-up of 6.2 years there were no statistically significant differences in ipsilateral breast tumor or axillary recurrence. Five-year regional recurrence rate was $0.9 \%$ for $\mathrm{SN}$ only compared to $0.5 \%$ for $\operatorname{ALND}(\mathrm{p}=0.11)$, with 5 year OS rates of $92.5 \%$ and $91.9 \%$, respectively ( $p=0.24)$. Of note, $82 \%$ of patients had received adjuvant systemic therapy. In $50 \%$ of patients the SN contained micrometastatic disease. 
How should we now interpret these new findings together with existing data? On the one hand, conventional pre-SN studies showed reduced survival rates from omission of ALND in clinically node-negative breast cancer patients. In SN positive series the overall ARR was 2.8 times higher than for the single group studies in SN negative patients, with estimated ARR after 5 and 8 years as high as $13 \%$ and $18 \%$. On the other hand, in the one randomized phase III study omission of ALND did not result in high ARRs or reduced survival. One explanation could be the increasing use of systemic therapy over the last decade that also reduces the risk of locoregional recurrences. Another explanation could be the increased use of pre operative screening of the axilla by ultrasound, causing stage migration of clinically nodenegative disease. Apparently, the challenge will be to better define the patients that still need to undergo a completion ALND versus those who do not. The risk of non$\mathrm{SN}$ metastases, if the axilla is left untreated, is on average $8 \%$ for $\mathrm{SN}$ negative disease, $12 \%$ for $\mathrm{SN}$ isolated tumor cells, $29 \%$ for micrometastases and $38 \%$ for macrometastases $[86,87]$. The risk of non-SN involvement is not only associated with $\mathrm{SN}$ status, but also with primary tumor size and presence or absence of lymph vessel invasion [86]. In the ACoSOG Z0011 study, 27\% of patients in the ALND group had positive non-SNs. Further research on predictive nomograms and on impact of modern adjuvant systemic therapy is needed to improve selection of patients who will not benefit from further axillary surgery. In the decision process the risk of arm morbidity should be taken into account, because even though morbidity from axillary surgery in the NSABP-B32 was lower than expected, shoulder deficit, arm volume difference, arm numbness and tingling occurred at least twice as frequently in the ALND arm as compared to the $\mathrm{SN}$ alone arm. 
We conclude that the SN procedure can be regarded as nearly optimal to identify patients who do not need an ALND, that is patients who have a negative SN. But, additional eligibility criteria and the role of systemic therapy need further to be elucidated to determine a potential role for avoiding ALND in selected SN-positive patients.

\section{Acknowledgement}

The authors thank Wim A.J.G. Lemmens for his assistance with statistical analyses. The authors thank the reviewer for his/her helpful comments regarding an earlier version of this article. 


\section{References}

1. Fisher B, Anderson S, Redmond CK, et al (1995): Reanalysis and results after 12 years of follow-up in a randomized clinical trial comparing total mastectomy with lumpectomy with or without irradiation in the treatment of breast cancer. N Engl J Med $333: 1456-1461$

2. Siesling S, van Dijck JA, Visser O, et al (2003): Trends in incidence of and mortality from cancer in The Netherlands in the period 1989-1998. Eur J Cancer 39:2521-2530

3. Giuliano AE, Chung AP (2010): Long-term follow-up confirms the oncologic safety of sentinel node biopsy without axillary dissection in node-negative breast cancer patients. Ann Surg 251:601-603

4. Ho VK, van der Heiden-van der Loo M, Rutgers EJ, et al (2008): Implementation of sentinel node biopsy in breast cancer patients in the Netherlands. Eur J Cancer 44:683691

5. Lyman GH, Giuliano AE, Somerfield MR, et al (2005): American Society of Clinical Oncology guideline recommendations for sentinel lymph node biopsy in early-stage breast cancer. J Clin Oncol 23:7703-7720

6. Veronesi U, Paganelli G, Viale G, et al (2003): A randomized comparison of sentinelnode biopsy with routine axillary dissection in breast cancer. N Engl J Med 349:546553

7. Veronesi U, Viale G, Paganelli G, et al (2010): Sentinel lymph node biopsy in breast cancer: ten-year results of a randomized controlled study. Ann Surg 251:595-600

8. Wasif N, Ye X, Giuliano AE (2009): Survey of ASCO members on management of sentinel node micrometastases in breast cancer: variation in treatment recommendations according to specialty. Ann Surg Oncol 16:2442-2449

9. Rosing DK, Dauphine CE, Vargas MP, et al (2006): Axillary regional recurrence after sentinel lymph node biopsy for breast cancer. Am Surg 72:939-942

10. Canavese G, Catturich A, Vecchio C, et al (2009): Sentinel node biopsy compared with complete axillary dissection for staging early breast cancer with clinically negative lymph nodes: results of randomized trial. Ann Oncol 20:1001-1007

11. Veronesi U, Galimberti V, Paganelli G, et al (2009): Axillary metastases in breast cancer patients with negative sentinel nodes: a follow-up of 3548 cases. Eur J Cancer 45:1381-1388 
12. Schulze T, Mucke J, Markwardt J, et al (2006): Long-term morbidity of patients with early breast cancer after sentinel lymph node biopsy compared to axillary lymph node dissection. J Surg Oncol 93:109-119

13. Zavagno G, De Salvo GL, Scalco G, et al (2008): A Randomized clinical trial on sentinel lymph node biopsy versus axillary lymph node dissection in breast cancer: results of the Sentinella/GIVOM trial. Ann Surg 247:207-213

14. Hayward J, Caleffi M (1987): The significance of local control in the primary treatment of breast cancer. Lucy Wortham James clinical research award. Arch Surg 122:12441247

15. Fisher B, Jeong JH, Anderson S, et al (2002): Twenty-five-year follow-up of a randomized trial comparing radical mastectomy, total mastectomy, and total mastectomy followed by irradiation. N Engl J Med 347:567-575

16. Louis-Silvestre C, Clough K, Asselain B, et al (2004): Axillary treatment in conservative management of operable breast cancer: dissection or radiotherapy? Results of a randomized study with 15 years of follow-up. J Clin Oncol 22:97-101

17. Hamilton T, Langlands O, Prescott RJ (1974): The treatment of operable cancer of the breast: a clinical trial in the South-East region of Scotland. Br J Surg 61:758-761

18. Johansen H, Kaae S, Schiodt T (1990): Simple mastectomy with postoperative irradiation versus extended radical mastectomy in breast cancer. A twenty-five-year follow-up of a randomized trial. Acta Oncologica 29:709-715

19. Kiluk JV, Ly QP, Meade T, et al (2010): Axillary Recurrence Rate Following Negative Sentinel Node Biopsy for Invasive Breast Cancer: Long-Term Follow-Up. Ann Surg Oncol 17:552-557

20. Gauthier T, Mollard J, Fermeaux V, et al (2009): Axillary recurrence after negative sentinel lymph node biopsy under local anesthesia in breast cancer. Eur J Surg Oncol 35:464-468

21. Groetelaers RP, van Berlo CL, Nijhuis PH, et al (2009): Axillary recurrences after negative sentinel lymph node biopsy under local anaesthesia for breast cancer: a followup study after 5 years. Eur J Surg Oncol 35:159-163

22. Sanli I, Lemaire BM, Muller AJ, et al (2009): Axillary recurrence after negative sentinel lymph node biopsy: frequency and factors influencing recurrence on the long term. Breast J 15:236-241 
23. Bulte CS, van der Heiden-van der Loo M, Hennipman A (2009): Axillary recurrence rate after tumour negative and micrometastatic positive sentinel node procedures in breast cancer patients, a population based multicenter study. Eur J Surg Oncol 35:25-31

24. Kim HJ, Son BH, Park EW, et al (2009): Axillary recurrence after negative sentinel lymph node biopsy. Breast Cancer Res Treat 114:301-305

25. van der Ploeg IM, Kroon BB, Antonini N, et al (2008): Axillary and extra-axillary lymph node recurrences after a tumor-negative sentinel node biopsy for breast cancer using intralesional tracer administration. Ann Surg Oncol 15:1025-1031

26. Christiansen P, Friis E, Balslev E, et al (2008): Sentinel node biopsy in breast cancer: five years experience from Denmark. Acta Oncol 47:561-568

27. Poletti P, Fenaroli P, Milesi A, et al (2008): Axillary recurrence in sentinel lymph nodenegative breast cancer patients. Ann Oncol 19:1842-1846

28. Bergkvist L, de Boniface J, Jonsson PE, et al (2008): Axillary recurrence rate after negative sentinel node biopsy in breast cancer: three-year follow-up of the Swedish Multicenter Cohort Study. Ann Surg 247:150-156

29. Kuijt GP, Roumen RM (2008): Second thoughts on sentinel lymph node biopsy in node-negative breast cancer. Br J Surg 95:310-311

30. van Wely BJ, Smidt ML, de Kievit IM, et al (2008): False-negative sentinel lymph node biopsy. Br J Surg 95:1352-1355

31. Heuts EM, van der Ent FW, Hulsewe KW, et al (2008): Incidence of axillary recurrence in 344 sentinel node negative breast cancer patients after intermediate follow-up. A prospective study into the accuracy of sentinel node biopsy in breast cancer patients. Acta Chir Belg 108:203-207

32. Domenech A, Benitez A, Bajen MT, et al (2007): Patients with breast cancer and negative sentinel lymph node biopsy without additional axillary lymph node dissection: a follow-up study of up to 5 years. Oncology 72:27-32

33. Konstantiniuk P, Schrenk P, Reitsamer R, et al (2007): A nonrandomized follow-up comparison between standard axillary node dissection and sentinel node biopsy in breast cancer. Breast 16:520-526

34. Susini T, Nori J, Vanzi E, et al (2007): Axillary ultrasound scanning in the follow-up of breast cancer patients undergoing sentinel node biopsy. Breast 16:190-196

35. Takei H, Suemasu K, Kurosumi M, et al (2007): Recurrence after sentinel lymph node biopsy with or without axillary lymph node dissection in patients with breast cancer. Breast Cancer 14:16-24 
36. de Kanter AY, Menke-Pluymers MM, Wouters MW, et al (2006): 5-Year follow-up of sentinel node negative breast cancer patients. Eur J Surg Oncol 32:282-286

37. Leikola J, Saarto T, Joensuu H, et al (2006): Ultrasonography of the axilla in the follow-up of breast cancer patients who have a negative sentinel node biopsy and who avoid axillary clearance. Acta Oncol 45:571-575

38. Nagashima T, Sakakibara M, Nakano S, et al (2006): Sentinel node micrometastasis and distant failure in breast cancer patients. Breast Cancer 13:186-191

39. Paajanen H, Kilponen VM, Heikkinen J, et al (2006): Feasibility of axillary ultrasound in the quality assessment of sentinel node biopsy in breast cancer surgery. Scand J Surg 95:195-198

40. Palesty JA, Foster JM, Hurd TC, et al (2006): Axillary recurrence in women with a negative sentinel lymph node and no axillary dissection in breast cancer. J Surg Oncol 93:129-132

41. Veronesi U, Paganelli G, Viale G, et al (2006): Sentinel-lymph-node biopsy as a staging procedure in breast cancer: update of a randomised controlled study. Lancet Oncol 7:983-990

42. Fan YG, Tan YY, Wu CT, et al (2005): The effect of sentinel node tumor burden on non-sentinel node status and recurrence rates in breast cancer. Ann Surg Oncol 12:705711

43. Jeruss JS, Winchester DJ, Sener SF, et al (2005): Axillary recurrence after sentinel node biopsy. Ann Surg Oncol 12:34-40

44. Khakpour N, Hunt KK, Kuerer HM, et al (2005): Sentinel lymph node dissection provides axillary control equal to complete axillary node dissection in breast cancer patients with lobular histology and a negative sentinel node. Am J Surg 190:598-601

45. Kokke MC, Jannink I, Barneveld PC, et al (2005): Incidence of axillary recurrence in 113 sentinel node negative breast cancer patients: a 3-year follow-up study. Eur J Surg Oncol 31:221-225

46. Langer I, Marti WR, Guller U, et al (2005): Axillary recurrence rate in breast cancer patients with negative sentinel lymph node (SLN) or SLN micrometastases: prospective analysis of 150 patients after SLN biopsy. Ann Surg 241:152-158

47. Sanjuan A, Vidal-Sicart S, Zanon G, et al (2005): Clinical axillary recurrence after sentinel node biopsy in breast cancer: a follow-up study of 220 patients. Eur J Nucl Med Mol Imaging 32:932-936 
48. Soni NK, Spillane AJ (2005): Experience of sentinel node biopsy alone in early breast cancer without further axillary dissection in patients with negative sentinel node. ANZ J Surg 75:292-299

49. Snoj M, Bracko M, Zagar I (2005): Axillary recurrence rate in breast cancer patients with negative sentinel lymph node. Croat Med J 46:377-381

50. Swenson KK, Mahipal A, Nissen MJ, et al (2005): Axillary disease recurrence after sentinel lymph node dissection for breast carcinoma. Cancer 104:1834-1839

51. Zavagno G, Carcoforo P, Franchini Z, et al (2005): Axillary recurrence after negative sentinel lymph node biopsy without axillary dissection: a study on 479 breast cancer patients. Eur J Surg Oncol 31:715-720

52. Imoto S, Wada N, Murakami K, et al (2004): Prognosis of breast cancer patients treated with sentinel node biopsy in Japan. Jpn J Clin Oncol 34:452-456

53. Torrenga H, Fabry H, van der Sijp JR, et al (2004): Omitting axillary lymph node dissection in sentinel node negative breast cancer patients is safe: a long term follow-up analysis. J Surg Oncol 88:4-7

54. Naik AM, Fey J, Gemignani M, et al (2004): The risk of axillary relapse after sentinel lymph node biopsy for breast cancer is comparable with that of axillary lymph node dissection: a follow-up study of 4008 procedures. Ann Surg 240:462-8

55. van der Vegt B, Doting MH, Jager PL, et al (2004): Axillary recurrence after sentinel lymph node biopsy. Eur J Surg Oncol 30:715-720

56. van Wessem KJ, Meijer WS (2004): Sentinel lymph node biopsy in breast cancer: results of intradermal periareolar tracer injection and follow-up of sentinel lymph nodenegative patients. Breast 13:290-296

57. Badgwell BD, Povoski SP, Abdessalam SF, et al (2003): Patterns of recurrence after sentinel lymph node biopsy for breast cancer. Ann Surg Oncol 10:376-380

58. Blanchard DK, Donohue JH, Reynolds C, et al (2003): Relapse and morbidity in patients undergoing sentinel lymph node biopsy alone or with axillary dissection for breast cancer. Arch Surg 138:482-487

59. Estourgie SH, Nieweg OE, Valdes Olmos RA, et al (2003): Eight false negative sentinel node procedures in breast cancer: what went wrong? Eur J Surg Oncol 29:336340

60. Ponzone R, Biglia N, Maggiorotto F, et al (2003): Sentinel node dissection as definitive treatment for node negative breast cancer patients. Eur J Surg Oncol 29:703-706 
61. Chung MA, Steinhoff MM, Cady B (2002): Clinical axillary recurrence in breast cancer patients after a negative sentinel node biopsy. Am J Surg 184:310-314

62. Hansen NM, Grube BJ, Giuliano AE (2002): The time has come to change the algorithm for the surgical management of early breast cancer. Arch Surg 137:11311135

63. Loza J, Colo F, Nadal J, et al (2002): Axillary recurrence after sentinel node biopsy for operable breast cancer. Eur J Surg Oncol 28:897-898

64. Shivers S, Cox C, Leight G, et al (2002): Final results of the Department of Defense multicenter breast lymphatic mapping trial. Ann Surg Oncol 9:248-255

65. Bilimoria KY, Bentrem DJ, Hansen NM, et al (2009): Comparison of sentinel lymph node biopsy alone and completion axillary lymph node dissection for node-positive breast cancer. J Clin Oncol 27:2946-2953

66. Hwang RF, Gonzalez-Angulo AM, Yi M, et al (2007): Low locoregional failure rates in selected breast cancer patients with tumor-positive sentinel lymph nodes who do not undergo completion axillary dissection. Cancer 110:723-730

67. Park J, Fey JV, Naik AM, et al (2007): A declining rate of completion axillary dissection in sentinel lymph node-positive breast cancer patients is associated with the use of a multivariate nomogram. Ann Surg 245:462-468

68. Pejavar S, Wilson LD, Haffty BG (2006): Regional nodal recurrence in breast cancer patients treated with conservative surgery and radiation therapy $(\mathrm{BCS}+\mathrm{RT})$. Int $\mathrm{J}$ Radiat Oncol Biol Phys 66:1320-1327

69. Haid A, Knauer M, Koberle-Wuhrer R, et al (2006): Medium-term follow-up data after sentinel node biopsy alone for breast cancer. Eur J Surg Oncol 32:1180-5118

70. Chagpar A, Middleton LP, Sahin AA, et al (2005): Clinical outcome of patients with lymph node-negative breast carcinoma who have sentinel lymph node micrometastases detected by immunohistochemistry. Cancer 103:1581-1586

71. Fant JS, Grant MD, Knox SM, et al (2003): Preliminary outcome analysis in patients with breast cancer and a positive sentinel lymph node who declined axillary dissection. Ann Surg Oncol 10:126-130

72. Guenther JM, Hansen NM, DiFronzo LA, et al (2003): Axillary dissection is not required for all patients with breast cancer and positive sentinel nodes. Arch Surg $138: 52-56$

73. Green FL, Page DL, Fleming ID, et al (2002): American Joint Committee on Cancer Staging Manual 6th ed. Philadelphia, PA, Springer 
74. Orr RK (1999): The impact of prophylactic axillary node dissection on breast cancer survival--a Bayesian meta-analysis. Ann Surg Oncol 6:109-116

75. White RE, Vezeridis MP, Konstadoulakis M, et al (1996): Therapeutic options and results for the management of minimally invasive carcinoma of the breast: influence of axillary dissection for treatment of T1a and T1b lesions. J Am Coll Surg 183:575-582

76. Bland KI, Scott-Conner CEH, Menck H, et al (1999): Axillary Dissection in BreastConserving Surgery for Stage I and II Breast Cancer: A National Cancer Data Base Study of Patterns of Omission and Implications for Survival. J Am Coll Surg 188:586596

77. Weir L, Speers C, D'yachkova Y, et al (2002): Prognostic Significance of the Number of Axillary Lymph Nodes Removed in Patients With Node-Negative Breast Cancer. J Clin Oncol 20:1793-1799

78. Krag DN, Single RM (2003): Breast Cancer Survival According to Number of Nodes Removed. Ann Surg Oncol 10:1152-1159

79. Polednak AP (2003): Survival of Lymph Node-Negative Breast Cancer Patients in relation to number of lymph nodes examined. Ann of Surg 237:163-167

80. Axelsson CK, Düring M, Christiansen PM, et al (2009): Impact on regional recurrence and survival of axillary surgery in women with node-negative primary breast cancer. $\mathrm{Br}$ J Surg 96:40-46

81. Krag DN (2010): Primary outcome results of NSABP B-32, a randomized phase III clinical trial to compare sentinel node resection (SNR) to conventional axillary dissection (AD) in clinically node-negative breast cancer patients. 2010 ASCO annual meeting. Chicago, 2010, \#CRA505

Nodes Removed. Ann Surg Oncol 10:1152-1159

82. Giuliano AE: ACOSOG Z0011 (2010): A randomized trial of axillary node dissection in women with clinical T1-2 N0 M0 breast cancer who have a positive sentinel node, 2010 ASCO annual meeting. Chicago, 2010, \#CRA506

83. Rescigno J, Zampell JC, Axelrod D (2009): Patterns of axillary surgical care for breast cancer in the era of sentinel lymph node biopsy. Ann Surg Oncol 16:687-696

84. Tjan-Heijnen VC, Pepels MJ, de Boer M, et al (2009): Impact of omission of completion axillary lymph node dissection (cALND) or axillary radiotherapy (ax RT) in breast cancer patients with micrometastases $(\mathrm{pN} 1 \mathrm{mi})$ or isolated tumor cells $(\mathrm{pNO}[\mathrm{i}+])$ in the sentinel lymph node $(\mathrm{SN})$ : Results from the MIRROR study, American Society of Clinical Oncology 2009. Orlando, FL, 2009, CRA506 
85. de Boer M, van Deurzen CH, van Dijck JA, et al (2009): Micrometastases or isolated tumor cells and the outcome of breast cancer. N Engl J Med 361:653-663

86. Bolster MJ, Peer PG, Bult P, et al (2007): Risk factors for non-sentinel lymph node metastases in patients with breast cancer. The outcome of a multi-institutional study. Ann Surg Oncol 14:181-189

87. van Deurzen CH, de Boer M, Monninkhof EM, et al (2008): Non-sentinel lymph node metastases associated with isolated breast cancer cells in the sentinel node. J Natl Cancer Inst. 22:1574-1580 
Table 1. Axillary recurrence rates with versus without axillary lymph node dissection (ALND) in patients with clinically node-negative breast cancer

\begin{tabular}{|c|c|c|c|c|c|c|}
\hline Study & $\begin{array}{c}\text { Patients } \\
\text { (N) }\end{array}$ & $\begin{array}{l}\text { pT1 } \\
(\%)\end{array}$ & $\begin{array}{c}\text { Node } \\
\text { positive } \\
\text { with } \\
\text { ALND (\%) }\end{array}$ & $\begin{array}{c}\text { Follow- } \\
\text { up } \\
\text { (months) }\end{array}$ & $\begin{array}{c}\text { Axillary } \\
\text { recurrence } \\
\text { with ALND } \\
(\%)\end{array}$ & $\begin{array}{c}\text { Axillary } \\
\text { recurrence } \\
\text { no ALND } \\
(\%)\end{array}$ \\
\hline Guy I ${ }^{14}$ & 232 & 17 & 24 & $60-120$ & 0.9 & 18.8 \\
\hline Guy $\|^{14}$ & 258 & 38 & - & $60-120$ & 1.4 & 12.5 \\
\hline NSABP-B04 ${ }^{15}$ & 727 & - & 39 & 120 & 1.4 & 18.4 \\
\hline
\end{tabular}


Table 2. Axillary recurrence after sentinel (SN)-only in SN-negative breast cancer patients in relation to tumor size and type of AST: Single group studies

\begin{tabular}{|c|c|c|c|c|c|c|}
\hline Source (reference) & $\begin{array}{c}\text { No. } \\
\text { patients }\end{array}$ & $\begin{array}{c}\% \mathrm{~T} 1 \text { or } \\
\text { median (range) }\end{array}$ & $\begin{array}{c}\text { \% chemo- } \\
\text { therapy I } \\
\text { hormonal } \\
\text { therapy }\end{array}$ & $\begin{array}{l}\text { Median } \\
\text { FU, mo } \\
\text { (range) }\end{array}$ & $\begin{array}{l}\text { Timing of } \\
\text { recurrence, mo }\end{array}$ & $\begin{array}{c}\text { Axillary } \\
\text { recurrence (\%) }\end{array}$ \\
\hline 2009 Canavese $(R)^{10}$ & 77 & $87 \%{ }^{*}$ & NR & $68(+/-17)$ & & 0 \\
\hline 2009 Veronesi11 & 3548 & $84 \%$ & $19 / 81$ & $48(-132)$ & 29 (range $2-86$ ) & 0.9 \\
\hline 2009 Kiluk $^{19}$ & 1530 & $14 \mathrm{~mm}$ & $26 / 53$ & $60(0-144)$ & $23,46,102,110$ & 0.3 \\
\hline 2009 Gauthier20 & 194 & $15 \mathrm{~mm}(1-31)$ & $27 / 77$ & $40(7-72)$ & - & 0 \\
\hline 2009 Groetelaers ${ }^{21}$ & 254 & $71 \%{ }^{*}$ & NR & $73(60-100)$ & 40 & 0.4 \\
\hline 2009 Sanli22 & 121 & $81 \%$ & 37 (total) & $44(15-76)$ & $24,31,32$ & 2.5 \\
\hline 2009 Bulte 23 & 503 & $71 \%^{*}$ & $21 / 23^{*}$ & $46(11-64)$ & $3,30,51$ & 0.6 \\
\hline $2009 \mathrm{Kim}^{24}$ & 293 & $82 \%{ }^{*}$ & NR & $40(24-49)$ & $8,12,16$ & 1.0 \\
\hline 2008 Zavagno $(\mathrm{R})^{13}$ & 218 & $81 \% *$ & 'to most' & $\begin{array}{c}56 \text { (IQ 42- } \\
63 \text { ) }\end{array}$ & NR & 0.5 \\
\hline 2008 Ploeg ${ }^{25}$ & 748 & $75 \%{ }^{*}$ & $21 / 23$ & $46(0-98)$ & 10,44 & 0.3 \\
\hline 2008 Christiansen 26 & 3717 & $68 \% *$ & NR & $20(0-62)$ & range $0-50$ & 0.5 \\
\hline 2008 Poletti27 & 804 & $79 \%$ & $18 / 82$ & $39(4-97)$ & $4,11,18,19,22,72$ & 0.7 \\
\hline 2008 Bergkvist ${ }^{28}$ & 2246 & $14 \mathrm{~mm}(5-30)$ & $\mathrm{NR}$ & $37(0-75)$ & $21(4-51)$ & 1.2 \\
\hline 2008 Kuijt29 & 100 & 15 mm (3-31) & $13 / 39$ & $78(4-103)$ & $14,20,33,79,90$ & 5.0 \\
\hline 2008 Wely30 & 392 & NR & NR & $65(33-123)$ & $27(4-63)$ & 2.8 \\
\hline 2008 Heuts $^{31}$ & 344 & $63 \%$ & NR & $43(1-96)$ & $17,21,26$ & 0.9 \\
\hline 2007 Domenech $^{32}$ & 91 & $85 \%$ & NR & $49(26-63)$ & - & 0 \\
\hline 2007 Konstantiniuk 33 & 1394 & $70 \% *$ & $24 / 79^{*}$ & $34(0-102)$ & $0-48$ & 0.4 \\
\hline 2007 Susini34 & 165 & $95 \%$ & $40 / 67$ & $46(12-72)$ & - & 0 \\
\hline 2007 Takei $^{35}$ & 822 & $39 \% *$ & 75 (total) & $34(2-83)$ & $9,18,21,29$ & 0.5 \\
\hline 2006 Rosing $^{9}$ & 89 & $19 \mathrm{~mm}(+/-14)$ & NR & $26(-48)$ & $N R$ & 1.1 \\
\hline 2006 Schulze ${ }^{12}$ & 25 & $100 \% *$ & $3 / 68^{*}$ & $47(+/-15)$ & - & 0 \\
\hline 2006 de Kanter 36 & 149 & $56 \% \mathrm{~T} 1 \mathrm{c}$ & 13 (total) & $65(50-79)$ & $10,12,14,56$ & 2.7 \\
\hline 2006 Leikola ${ }^{37}$ & 205 & $81 \%$ & $45 / 55$ & $36(0-36)$ & 24,36 & 1.0 \\
\hline 2006 Nagashima38 $^{38}$ & 241 & 8 mm (+/- 9) & $16 / 76$ & $27(6-66)$ & - & 0 \\
\hline 2006 Paajanen ${ }^{39}$ & 107 & $63 \%{ }^{*}$ & $44 / 57^{*}$ & $31(13-49)$ & - & 0 \\
\hline 2006 Palesty40 & 335 & $83 \%$ & $32 / 76$ & $33(2-76)$ & 5,14 & 0.6 \\
\hline 2006 Veronesi $(R)^{7,41}$ & 167 & $100 \%$ & $47 / 90^{*}$ & $79(15-97)$ & 86 & 0.6 \\
\hline 2005 Fan42 & 237 & $13 \mathrm{~mm}(1-60)$ & NR & $31(0-70)$ & 5,18 & 0.8 \\
\hline 2005 Jeruss $^{43}$ & 592 & $74 \%{ }^{*}$ & $42 / 70^{*}$ & $27(1-98)$ & 22 & 0.2 \\
\hline 2005 Khakpour 44 & 202 & NR & $44 / 86$ & $26(6-80)$ & - & 0 \\
\hline 2005 Kokke $^{45}$ & 113 & 14 mm (2-35) & $19 / 18$ & $38(24-54)$ & 29 & 0.9 \\
\hline 2005 Langer ${ }^{46}$ & 122 & $72 \%^{*}$ & $20 / 76$ & $42(12-64)$ & 14 & 0.8 \\
\hline 2005 Sanjuan ${ }^{47}$ & 158 & 17 mm (0-36) & NR & $21(4-45)$ & 17 & 0.6 \\
\hline 2005 Soni 48 & 101 & $75^{*}$ & $21 / 71$ & $22(6-42)$ & 35 & 1.0 \\
\hline 2005 Snoj49 & 50 & 13 mm (5-25) & NR & $32(10-50)$ & 26 & 2.0 \\
\hline 2005 Swenson $^{50}$ & 580 & $85 \%^{*}$ & $42 / 58$ & $33(2-73)$ & $11,24,36$ & 0.5 \\
\hline 2005 Zavagno $^{51}$ & 479 & $90 \%$ & $53 / 47$ & $36(12-68)$ & - & 0 \\
\hline 2004 Imoto $^{52}$ & 112 & $56 \%$ & $32 / 17$ & $44(36-53)$ & $3-22$ & 4.5 \\
\hline 2004 Torrenga ${ }^{53}$ & 104 & $15 \mathrm{~mm}(4-50)$ & 19 (total) & $57(48-83)$ & 24 & 1.0 \\
\hline 2004 Naik $^{54}$ & 2340 & $89 \%$ & NR & $31(1-75)$ & $19,29,38$ & 0.1 \\
\hline 2004 van der Vegt55 & 106 & $71 \%{ }^{*}$ & 24 (total) & $35(17-59)$ & 26 & 0.9 \\
\hline 2004 Wessem $^{56}$ & 56 & $58 \%$ & NR & $28(16-39)$ & 24 & 1.8 \\
\hline 2003 Badgwell57 & 159 & 71 & NR & $32(24-34)$ & - & 0 \\
\hline 2003 Blanchard 58 & 685 & 78 & $26 / N R$ & $29(7-46)$ & 41 & 0.1 \\
\hline 2003 Estourgie 59 & 361 & NR & NR & $16(1-34)$ & 22 & 0.3 \\
\hline 2003 Ponzone 60 & 150 & 80 & NR & $15(3-35)$ & - & 0 \\
\hline 2002 Chung61 & 206 & 81 & 27 / 47 & $26(2-50)$ & $4,11,40$ & 1.5 \\
\hline 2002 Hansen 62 & 238 & 85 & $25 / 56$ & $39(6-69)$ & - & 0 \\
\hline 2002 Loza63 & 168 & NR & NR & $21(1-48)$ & 30 & 0.6 \\
\hline
\end{tabular}


M. Pepels et al.

\section{Legend Table 2}

${ }^{*}$ characteristics including patients with a positive SN; DCIS excluded, whenever information was available; (R) indicates part of a randomized trial; NR, patients received systemic therapy, but exact percentage was not reported 
Table 3. Studies in which breast cancer patients with a negative SN were randomized between a completion axillary lymph node dissection (ALND)-or-not, and of studies in which patients with a negative SN in the learning / validation phase routinely underwent a completion ALND, whereas the next patients with a negative SN did not undergo a completion ALND anymore (SN application phase)

\begin{tabular}{|c|c|c|c|c|c|c|c|}
\hline Source $\$$ & $\begin{array}{c}\text { Only Sn } \\
\text { negative pts } \\
\text { are included }\end{array}$ & $\begin{array}{l}\text { Pts } \\
\text { (No) }\end{array}$ & $\begin{array}{l}\% \mathrm{~T} 1 \text { (or } \\
\text { median, } \\
\text { range in } \\
\mathrm{mm} \text { ) }\end{array}$ & $\begin{array}{l}\text { Follow-up, mo } \\
\text { (median, range) }\end{array}$ & $\begin{array}{c}\text { Axillary } \\
\text { recurrence } \\
(\%)\end{array}$ & $\begin{array}{l}\text { Pos. } \\
\text { non- } \\
\text { SNs } \\
(\%)\end{array}$ & $\begin{array}{c}\text { False } \\
\text { negative } \\
\text { rate }(\%)\end{array}$ \\
\hline \multicolumn{8}{|l|}{ Randomized trials } \\
\hline \multirow[t]{2}{*}{2009 Canavese $^{10}$} & SN and ALND & 88 & $74^{*}$ & mean $67(+/-16)$ & 1.1@/NR & 9.2 & 22.2 \\
\hline & SN only & 79 & $87^{*}$ & mean $67(+/-16)$ & 0 & & \\
\hline \multirow[t]{2}{*}{2008 Zavagno $^{13}$} & SN and ALND & 233 & $82^{*}$ & 56 (IQ 42-63) & 0 & 7.7 & 16.7 \\
\hline & SN only & 218 & $81^{*}$ & 56 (IQ 42-63) & 0.5 & & \\
\hline \multirow[t]{2}{*}{2006 Veronesi ${ }^{7,41}$} & SN and ALND & 174 & 100 & $79(5-97)$ & 0 & 4.6 & 8.8 \\
\hline & SN only & 167 & 100 & $79(5-97)$ & 0.6 & & \\
\hline \multicolumn{8}{|l|}{$\begin{array}{l}\text { Studies reporting } \\
\text { on Validation and } \\
\text { next Application } \\
\text { phase }\end{array}$} \\
\hline \multirow[t]{2}{*}{$2009 \mathrm{Kim}^{24}$} & SN and ALND & 174 & $73^{*}$ & $40(24-49) \#$ & 0 & & \\
\hline & SN only & 293 & $73^{*}$ & 40 (24-49)\# & 1.0 & & \\
\hline \multirow{2}{*}{2007 Konstantiniuk ${ }^{33}$} & SN and ALND & 355 & $69^{*}$ & $47(0-102)$ & 0.8 & 3.7 & 6.5 \\
\hline & SN only & 1394 & $70^{*}$ & $31(0-87)$ & 0.4 & & \\
\hline \multirow[t]{2}{*}{2007 Takei35 } & SN and ALND & 56 & 30 & $34(2-83) \#$ & 0 & & \\
\hline & SN only & 1062 & 34 & $34(2-83) \#$ & 0.4 & & \\
\hline \multirow[t]{2}{*}{2006 Schulze ${ }^{12}$} & SN and ALND & 56 & 100 & $66+/-22$ & 0 & 7.1 & 12.1 \\
\hline & SN only & 25 & 100 & $47+/-15$ & 0 & & \\
\hline \multirow[t]{2}{*}{2005 Fan ${ }^{42}$} & SN and ALND & 39 & $13(1-60)^{*}$ & $31(0.3-70) \#$ & 0 & 5.1 & \\
\hline & SN only & 237 & $13(1-60)^{*}$ & 31 (0.3-70)\# & 0.8 & & \\
\hline \multirow{2}{*}{2004 Jeruss $^{43}$} & SN and ALND & 30 & $71^{*}$ & $27(1-98) \#$ & 3.3 & 2.0 & \\
\hline & SN only & 557 & $71^{*}$ & $27(1-98) \#$ & 0.2 & & \\
\hline \multirow[t]{2}{*}{2004 Imoto 52} & SN and ALND & 97 & 31 & $62(53-71)$ & 0 & & \\
\hline & SN only & 112 & 56 & $44(36-52)$ & 4.5 & & \\
\hline \multirow{2}{*}{2004 Naik $^{54}$} & SN and ALND & 326 & 66 & $32(1-74)$ & 0 & & \\
\hline & SN only & 2340 & 89 & $31(1-75)$ & 0.1 & & \\
\hline \multirow[t]{2}{*}{2002 Shivers $^{64}$} & SN and ALND & 250 & $96 \% \mathrm{~T} 1,2^{*}$ & $16(12-42)$ \# & 0 & 2.0 & 4.1 \\
\hline & SN only & 180 & $96 \% \mathrm{~T} 1,2^{*}$ & $16(12-42) \#$ & 0 & & \\
\hline
\end{tabular}


M. Pepels et al.

\section{Legend table 3:}

${ }^{\$}$ Only studies that included consecutively all patients with a negative SN irrespective of non-SN status and with follow-up information with and without ALND were included (so, different from the main results of randomized trials, in which intent-to-treat analyses was performed irrespective of SN status).

Only pts with negative $\mathrm{SN}$ are included in this table

* Tsize also included of patients from other categories (eg. Positive SN)

\# Follow-up time in validation studies: only median provided for total study population, whereas in reality follow-up of 'SN and ALND' group was somewhat longer than of the more recent 'SN only' group. In some studies, the range of follow-time was estimated from date of inclusion versus date of analysis

@ unclear whether this one patient with an axillary recurrence had a positive or a negative SN Positive non-SN rate and False negative rate were calculated only for those studies that provided full information on the validation phase including patients with a positive SN

$\mathrm{NR}=$ not reported

$I Q$ : interquartile range 
Table 4. Axillary recurrence rate in studies on selected SN-positive breast cancer patients who did not undergo completion axillary lymph node dissection (ALND)

\begin{tabular}{|c|c|c|c|c|c|c|c|}
\hline Source & $\begin{array}{l}\text { No } \\
\text { pts }\end{array}$ & $\% \mathrm{~T} 1$ & $\begin{array}{c}\text { AST \% } \\
\text { chemo / } \\
\text { hormonal }\end{array}$ & $\begin{array}{c}\mathrm{RT} \\
\text { axilla } \\
\% \\
\end{array}$ & SN status & $\begin{array}{c}\text { Median FU } \\
\text { (months) }\end{array}$ & $\begin{array}{c}\text { Axillary } \\
\text { recurrence } \\
\%\end{array}$ \\
\hline 2009 Bulte 23 & 20 & $71^{*}$ & $21 / 23^{*}$ & NR & 20 "micro" & $46(11-64)$ & 0 \\
\hline 2009 Bilimoria 65 & 1,988 & 63 & $71 / 41$ & $N R$ & 530“micro"; 1,458macro & $64(60-72)$ & $0.6 / 1.2$ \\
\hline 2007 Takei $^{35}$ & 120 & 30 & 92 & 54 & Not specified & $34(2-83)^{\star}$ & 0 \\
\hline 2007 Hwang 66 & 196 & 72 & $56 / 27$ & 64 & 67itc; 90micro; 39macro & $30(1-62)$ & 0 \\
\hline 2007 Park 67 & 287 & 78 & NR & 15 & Not specified & $23(6-87)$ & $2.1(5.0)^{\wedge}$ \\
\hline 2006 Schulze ${ }^{12}$ & 6 & $100^{*}$ & $3 / 68^{*}$ & - & 1itc; 4micro; 1 macro & $49+/-17^{*}$ & 0 \\
\hline 2006 Pejavar68 & 16 & $80^{*}$ & $30 / 34^{*}$ & 100 & Not specified & $24-60^{*}$ & 0 \\
\hline 2006 Haid $^{69}$ & 10 & $77^{*}$ & $32 / 93^{*}$ & - & 2itc; 6micro; 2macro & $47(7-90)$ & 0 \\
\hline 2005 Fan $^{42}$ & 38 & 71 & $N R$ & 63 & 27micro; 11 macro & $29(6-76)$ & 2.6 \\
\hline 2005Jeruss ${ }^{43}$ & 73 & $57^{*}$ & $85 / 70^{*}$ & - & 73 "micro" & $27(1-98)$ & 0 \\
\hline 2005 Langer $^{46}$ & 27 & $72^{*}$ & 20 / 76@ & - & 27 "micro" & $42(12-64)$ & 0 \\
\hline 2005 Swenson 50 & 67 & $82^{*}$ & $42 / 58^{*}$ & - & 32 itc; 31 micro; 4 macro & $33(2-73)$ & 1.5 \\
\hline 2005 Chagpar $^{70}$ & 15 & $89^{*}$ & 33 & - & 2itc; 12micro; 1macro & $40(1-54)$ & 0 \\
\hline 2004 Vegt55 & 10 & $85^{*}$ & NR & 100 & 4micro; 6macro & $35(17-59)$ & 0 \\
\hline 2003 Fant $^{71}$ & 31 & 81 & 100 & 3 & 27"micro"; 4macro & $28(21-48)$ & 0 \\
\hline 2003 Guenther ${ }^{72}$ & 46 & 67 & 100 & 2 & 23itc; 16 "micro"; 7 macro & $32(4-61)$ & 0 \\
\hline
\end{tabular}

\section{Legend table 4:}

* total group, not specified separately for SN-positive patients

"micro": before 2002 there was no distinction between itc/micro, and these were, therefore, referred to as "micro"

@ for all SN only including both SN negatives as positives

^ axillary relapse rate if positive $\mathrm{SN}$ was detected by H\&E

NR, patients received systemic therapy, but exact percentage was not reported 
Figure 1. Kaplan Meier curves for the percentage axillary recurrence among patients with a negative SN who did not undergo a completion ALND, based on 50 observational series (Table 2). As the curves cannot be determined with certainty, the bold line shows the recurrence for the middle scenario, whereas the other lines indicate the recurrence for extreme best case and worst case scenarios, respectively. The numbers at risk correspond to the middle scenario.

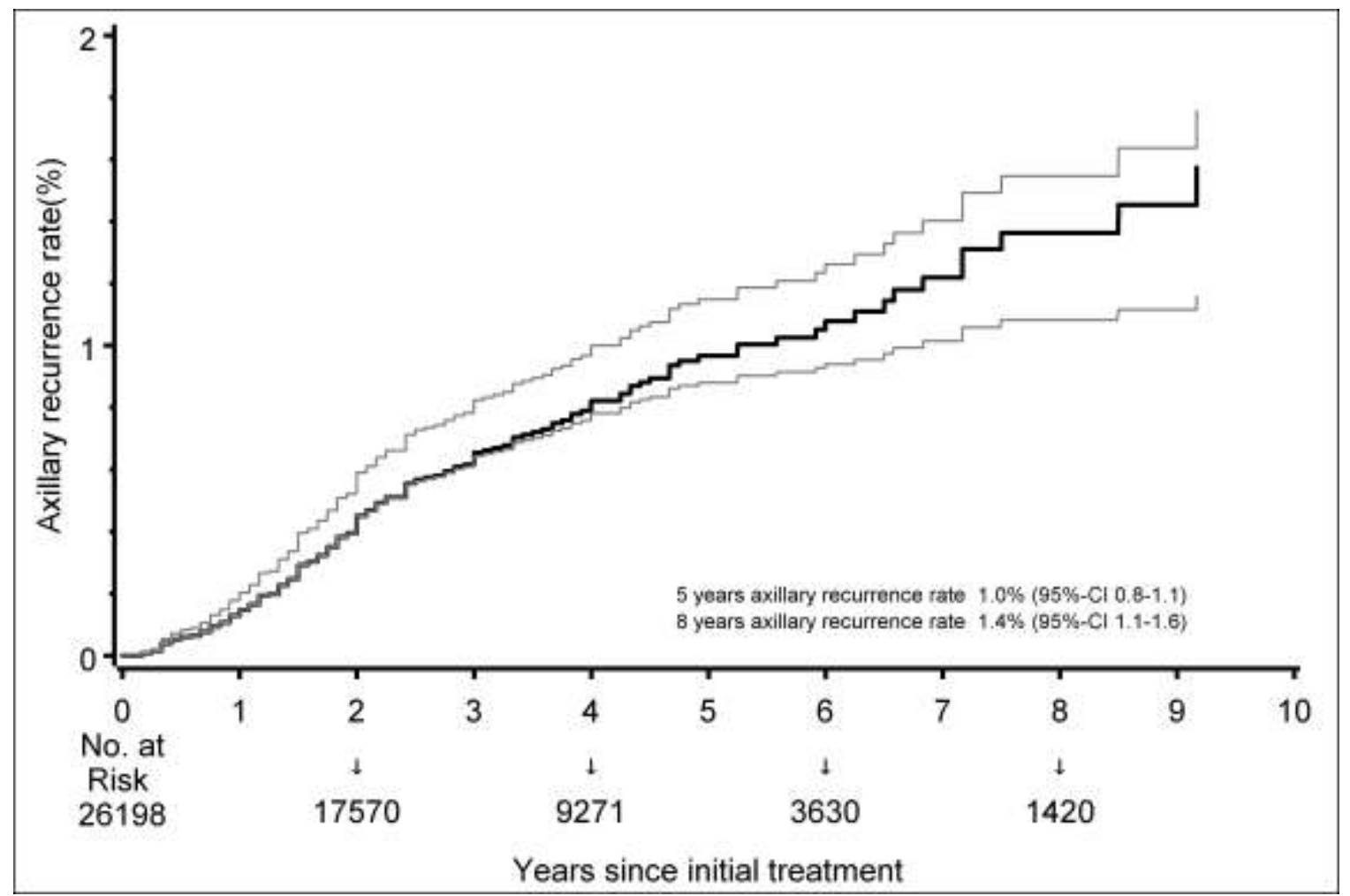


Table 5. OS rates of clinically node-negative breast cancer patients: randomized trials, ALND vs no ALND (Orr); pre SN-database studies ( $\mathrm{n}=$ 160,459), and randomized trials, SN with on indication ALND vs ALND in all patients (pooled analysis 1,179)

\begin{tabular}{|c|c|c|c|c|c|c|c|}
\hline Trial & No. pts & FU (yrs) & Comparison & Individual studies OS (\%) & HR OS in MVA for ALND & $\begin{array}{c}\text { Summary statistics } \\
\text { OS benefit ALND }\end{array}$ & Remarks \\
\hline Orr's meta-analysis ${ }^{74}$ & 2,936 & & & & & $5.4 \%(95 \% \mathrm{Cl} 2.7 .8 .0)$ & Essentially no AST \\
\hline Guy's $\left.\right|^{14}$ & 370 & 10 & No ALDND vs ALND & 44 vs 52 & & & \\
\hline Guy's II14 & 258 & 10 & No ALDND vs ALND & 57 vs 73 & & & \\
\hline B- $04^{15}$ & 727 & 10 & No ALDND vs ALND & 54 vs 58 & & & \\
\hline Curie $^{16}$ & 658 & 5 & No ALDND vs ALND & 93 vs 97 & & & \\
\hline SES17 & 498 & 10 & No ALDND vs ALND & 52 vs 61 & & & \\
\hline Copenhagen ${ }^{18}$ & 425 & 10 & No ALDND vs ALND & 46 vs 50 & & & \\
\hline Database studies & 160,459 & & & & & & \\
\hline White, RI-TR75 & 1,126 & 5 & No ALDND vs ALND & 64 vs 88 & 0.21 for BCS and 0.48 for MRM & & $P<0.001 ;$ MVA not including AST \\
\hline Bland, $\mathrm{NCDB}^{76}$ & 6,753 & 10 & No ALDND vs ALND & 85 vs 94 & nd & & OS for stage I: BCS+RT, no AST \\
\hline Weir, BCCA ${ }^{77}$ & 2,278 & 10 & $<10$ vs $10+$ nodes resected & no AST: 75 vs 80; AST: 75 vs 79 & NS & & $\mathrm{P}=0.06$ (no AST); $\mathrm{p}=0.57$ (with AST) \\
\hline Krag, SEER ${ }^{78}$ & 72,102 & 10 & $<10$ vs $10+$ nodes resected & pN0: 75 vs 78; pN1-3: 54 vs 65 & $\begin{array}{l}0.95(0.93-0.97) \text { for } \mathrm{pN0} / \\
0.91(0.76-0.94) \text { for } \mathrm{pN} 1-3\end{array}$ & & $\begin{array}{l}\text { MVA not for AST; OS rates shown for } \\
\text { patient category of } 50 \text { to } 80 \text { yrs }\end{array}$ \\
\hline Polednak, SEER ${ }^{79}$ & 69,543 & 5 & $<10$ vs $10+$ nodes resected & & $0.65(95 \% \mathrm{Cl} 0.51-0.83)$ & & $\begin{array}{l}\text { MVA not for AST, HR shown for 1-3 } \\
\text { nodes }\end{array}$ \\
\hline Axelsson, DBCG80 & 8,657 & 9 & $<10$ vs $10+$ nodes resected & $75 \%$ & $0.90(95 \% \mathrm{Cl} 0.82-0.99)$ & & None of the pts used AST \\
\hline Randomized SN studies & 1,179 & & & & & $-0.2(95 \% \mathrm{Cl}-2.4,2.2)$ & Pooled analyses on 5 -years OS rates \\
\hline Canavese $^{10}$ & 225 & 5 & SN/ALND vs ALND & 97 vs 97 & & & Well balanced, but no info on AST \\
\hline Zavagno ${ }^{13}$ & 697 & 5 & SN/ALND vs ALND & 95 vs 96 & & & Well balanced, but no info on AST \\
\hline Veronesi 41 & 257 & 5 & SN/ALND vs ALND & 98 vs 96 & & & Well balanced, but no info on AST \\
\hline
\end{tabular}

RI-TR, Rhode Island Tumor Registry; NCDB, National Cancer Data Base; BCCA, British Columbia Cancer Agency; SEER, Surveillance, Epidemiology and End Results; DBCG, Danish Breast Cancer Group; FU, follow-up; ALND, axillary lymph node dissection; SN, sentinel node; OS, OS; AST, adjuvant systemic therapy; HR, hazard ratio; MVA, multivariate analysis; BCS, breast conserving surgery; MRM, modified radical mastectomy; nd, note done; NS, not significant; RT, radiotherapy. 